\title{
Genetic Impact on Bone Modulation-A Review Bridging Bioscience to Genetic Engineering
}

\author{
Anulekha Avinash C.K. ${ }^{1}$ Harshini Tholupunuri ${ }^{1}$ \\ Dilip Jayyarapu ${ }^{2}$ Sangeeta $\mathrm{Nair}^{3}$
${ }^{1}$ Kamineni Institute of Dental Sciences, Narketpally, Telangana, India
${ }^{2}$ Department of Prosthodontics, Kamineni Institute of Dental
Sciences, Narketpally, Telangana, India
${ }^{3}$ Department of Prosthodontics Anoor Dental College,
Muvattupuzha, Kerala, India \\ Global Med Genet 2021;8:51-56.
}

M. Ramu Reddy ${ }^{2}$ Mamatha Muralidhar ${ }^{2}$

\begin{abstract}
Address for correspondence Anulekha Avinash C.K., MDS, Kamineni Institute of Dental Sciences, Narketpally 508254, Telangana, India (e-mail: anulekhaavinash@gmail.com).
\end{abstract}

\begin{abstract}
- Keywords

- genetic mutations syndromes bone resorption

Genes control approximately $60 \%$ to $75 \%$ of the variance of peak bone mass/density and a much smaller amount of variance in rate of loss.

Bone mass increases during growth to a peak value and soon after begins to decline. Most of the genetic effect is exerted during growth and so influences peak bone mass; whether there is an additional genetic effect on the rate of bone loss is less clear. So, this article aims to place emphasis on various oral and systemic conditions that are manifested due to altered gene function. Genetic polymorphisms and mutations are simple, although the consequences of the mechanism are complex. The syndromic manifestation due to changes at genetic level will greatly affect the bone quality, which will ultimately affect any treatment prognosis. Hence, a better understanding of molecular mechanisms of bone remodeling helps to identify pathogenic causes of bone, skeletal diseases, and leads to the development of targeted therapies for these diseases. This review highlights notions on the connecting link between science and genetics as well as various oral scenarios where gene could bring about changes, resulting in deformities. There is an intense research awaited in the future which could intervene with the causes that bring about genetic modulations, so as to decrease the mortality rate of humans.
\end{abstract}

\section{Introduction}

Bone remodeling is a physiological process; if there exists an imbalance in the metabolic activities of the cells, the process turns to a pathological condition. Bone formation and resorption is a common process throughout the age, unless and until the process is disturbed by an etiology like hormonal disturbances, developmental anomalies, genetic variations, and so on. ${ }^{1-3}$ More often, ridge resorption is a common problem encountered with the elderly age group. This scenario is extremely challenging with prosthodontic view, as the
DOI https://doi.org/

10.1055/s-0041-1725069.

ISSN 2699-9404. available basal foundation is compromised to retain and support the prosthesis. Surgical intervention also becomes challenging due to fear of violating the vital structures. Relating the resorption to an oral scenario, one could describe the residual ridge as the shape of the clinical alveolar ridge after healing of bone and soft tissues posttooth extractions. A cascade of inflammatory reactions is activated immediately after tooth extraction, and the extraction socket is temporarily closed by the blood clotting. ${ }^{4}$ It is documented that residual ridge resorption is multifactorial by origin, which involves anatomic, metabolic, and mechanical factors. ${ }^{5}$ However, the

(C) 2021. The Author(s).

This is an open access article published by Thieme under the terms of the Creative Commons Attribution License, permitting unrestricted use, distribution, and reproduction so long as the original work is properly cited. (https://creativecommons.org/licenses/by/4.0/)

Georg Thieme Verlag KG, Rüdigerstraße 14, 70469 Stuttgart, Germany 
resorption to get accelerated requires the involvement of systemic conditions of health. With progression in age, especially females of menopausal age group undergo a lot of physiological changes, starting from the genetic level. ${ }^{6-8}$

The influence of the genes varies, bringing about changes at various levels of health. The ill effects of genetic changes, affecting various systems of the human body, is deleterious in its own way. However, our focus is particularly on the genetic changes influencing the skeletal system, especially the alveolar ridges. The quality and quantity of residual ridge is extremely significant, so as to sustain a healthy abutment around it as well as support the artificial prosthesis in areas where there is a need to substitute the missing teeth. Hence, the greater the quality of bone, better would be the prognosis of the dental treatment. ${ }^{9}$

There is a tremendous literature support which strongly proves that a genetic factor links an association between periodontitis, osteoporosis, and few syndromes that cause bone modulation. ${ }^{10-12}$ However, in all of the above-mentioned studies, the role of gene is vital. There is a need to study about the genetic factors, so as to explore the probabilities that could be considered in intervening with progression of the disease. The role of gene that is involved in bringing about the resorptive changes is complex and extremely interesting. Although there is documentation regarding the influence of various genes involved in creating various pathological changes in the human body, a considerable amount of research still needs to be conducted with regard to genetic factors involved which create and lead to progress bony changes.

Hence, an effort is made to gather the information regarding various types of genes involved in bone modulation of various types of compromised health conditions, affecting the harmony of the stomatognathic system. The article describes various health conditions where genes place emphasis on creating a compromise in health and devastating the existing condition. There is a possibility in future to intervene with the causes that bring about genetic changes, so as to decrease the mortality rate of humans. The advancement in the genetic engineering is likely to bring about a huge leap in the field of molecular genetics.

Virtually every single disease in human beings is directly or indirectly affected by genetic variation, conferring susceptibility, resistance, or interaction with environmental factors. Single nucleotide polymorphism (SNP) is the most common type of genetic variation, in which there is an alternate base occurring at a frequency greater than $1 \%$ in the human population. ${ }^{13}$

The correlation between SNPs in vascular endothelial growth factor and residual ridge resorption (RRR) was studied by Song and Lee among 120 Korean subjects with the edentulous mandible, observing a conspicuous relation between rs1570360 and haplotype A-C-C with RRR. The investigators affirm it as an unprecedented genetic marker for identifying people susceptible to severe RRR after dental extraction. ${ }^{14}$ Similarly, AlSheikh et al in a study not only showed an association between SNPs in IL10 and NOD2 genes but also revealed that the genotypes of the different SNPs affect health and bone resorption. Hence, identifying SNPs in genes which are vulnerable would not only allow us to have a better understanding of disease processes and their underlying mechanisms but also provide scope for more efficient treatment options against RRR. ${ }^{15}$

In the quest to unveil the role of genetic factors in the development of RRR, there has been few studies which investigated SNPs in different genes, including cytokine and growth factor genes, genes of matrix metalloproteinases (MMPs), fibroblast growth factor receptor (FGFR1), and hypoxia-inducible factor-1 (HIF-1 $\alpha$ ) and have showed marked associations between some polymorphisms and RRR. ${ }^{16-18}$ Sundar et al reported a positive correlation in terms of genetic association between SNPs of matrix metalloproteinase-1 (MMP-1) gene promoter and RRR of edentulous mandible. ${ }^{14}$

\section{Pathogenesis Associated with Various Conditions}

\section{After Tooth Extraction}

Normally bone undergoes continuous process of remodeling all the time through bone resorption and bone deposition. As mentioned earlier, the moment a tooth is extracted, there is injury to the blood vessels, followed by blocking of blood which, in turn, results in reduction of partial pressure of oxygen in the surrounding area. Now, as the tissues are in the state of hypoxia, this is when genetic factors come into the scene. HIF-1 is a transcriptional complex that plays an important role in cellular and systemic oxygen homeostasis. HIF- 1 consists of $\alpha$ and $\beta$ subunits. The $\alpha$ subunit, which determines HIF-1 activity, is regulated by oxygen tension. Since HIF- $1 \alpha$ gene is critical for oral-wound healing after extraction of teeth, and since it has a high genetic diversity, common SNPs in HIF- $1 \alpha$ could play a role in the appearance of severely resorbed mandibular ridges. ${ }^{19-21}$

At the macroscopic level, during early healing period of dental extraction wounds, the gingival margins contract toward the center of the extraction socket and there is reestablishment of epithelial integrity. This newly regenerated epithelium becomes a central part of the edentulous oral mucosa. It is relatively thick with elongated rete pegs suggestive of acanthosis. But in stark contrast, thickness of the connective tissue of the established residual ridge is found decreased in both denture wearers and nondenture wearers, whereas the collagen density is increased. ${ }^{22,23}$

All the above-mentioned findings highlight the fact that there is constant remodeling of the oral mucosa and contraction of connective tissue, which may result in a thin oral mucosa, a characteristic of atrophic edentulous residual ridge. ${ }^{24}$

\section{Periodontitis}

Another scenario where we see trademark bone loss is progressing periodontitis, and failure to prevent it poses a big challenge in providing effective treatment. Aggressive periodontitis which is also called "juvenile periodontitis" is considered to be prevalent in children and adolescents during circumpubertal period. It is characterized by rapid loss of connective tissue attachment and alveolar bone with familial aggregation. It is caused by both pathogenic microflora and 
abnormality in host defense mechanisms. Aggressive periodontitis can be localized or generalized. ${ }^{25}$ Localized aggressive periodontitis (LAgP) occurs in children and adolescents without clinical evidence of systemic disease and is characterized by the severe loss of alveolar bone around permanent teeth. ${ }^{26}$ Linkage studies of the Brandywine population (a segregated group of people in Maryland that represents a relatively closed gene pool) have found a gene conferring increased risk for LAgP on chromosome 4. ${ }^{27}$

In periodontal disease, the cellular inflammatory infiltrate of T cells, B cells, macrophages, and neutrophils within gingival connective tissue is increased which, in turn, leads to increased secretion of inflammatory mediators. ${ }^{28}$ These inflammatory cells also interact with stromal cells such as osteoblasts, periodontal ligament, and gingival fibroblasts. Bone resorption is primarily regulated by RANK signaling pathway, which plays a central role in osteoclast differentiate and function. Receptor activator of nuclear factor-kB ligand (RANKL) produced by lymphocytes do not play any role during normal conditions. But in an inflammatory pathological state such as periodontitis, it plays a major role in inflammatory bone resorption, which is mediated by activated T lymphocytes and B lymphocytes. These activated lymphocytes are found in large numbers in inflamed periodontal tissue. ${ }^{29,30}$

\section{Osteoporosis}

Osteoporosis is a common disease characterized by lowbone mass and defects in the microarchitecture of bone tissue, which impairs bone strength and leads to an increased risk of fragility fractures. - Table 1 shows several rare diseases that have been identified where profound effects on bone mass, bone fragility, and bone turnover occur as a result of mutations in single genes.

\section{Loci and Genes with Significant Evidence for Association with Bone Mineral Density (BMD)}

\section{ESR1}

Estrogen, by interacting with its receptors in bone and other tissues, plays an important role in regulating skeletal growth and maintaining bone mass. The estrogen receptor type 1

Table 1 Influence of genetic mutation in various diseases

\begin{tabular}{|l|l|l|}
\hline Disease & Gene & Defect in function \\
\hline $\begin{array}{l}\text { High bone mass } \\
\text { syndrome }\end{array}$ & LRP5a & $\begin{array}{l}\text { Increases bone formation } \\
\text { and inhibits bone resorption } \\
\text { by regulating OPG } \\
\text { production by osteoblast }\end{array}$ \\
\hline $\begin{array}{l}\text { Aromatase } \\
\text { deficiency }\end{array}$ & CYP17 & Osteoporosis \\
\hline $\begin{array}{l}\text { Estrogen receptor } \\
\text { deficiency }\end{array}$ & ESR1 & Osteoporosis, tall stature \\
\hline $\begin{array}{l}\text { Osteoporosis- } \\
\text { pseudoglioma } \\
\text { syndrome }\end{array}$ & $\begin{array}{l}\text { LRP5 } \\
\text { gene }\end{array}$ & $\begin{array}{l}\text { Low-bone mass and } \\
\text { increased bone fragility }\end{array}$ \\
\hline
\end{tabular}

Abbreviation: OPG, osteoprotegerin. gene (ESR1) is therefore a strong candidate for the genetic regulation of bone mass.

The association between ESR1 alleles and osteoporosis was confirmed by the deCODE GWAS, which showed a significant association with BMD and fracture. ${ }^{31,32}$

The osteoporosis-pseudoglioma syndrome is a rare recessive disorder characterized by low-bone mass and increased bone fragility that has been found to be caused by inactivating mutations in the LRP5 gene. Many different gene mutations like TCIRG1, CLCN7, OSTM1, and NEMO have been identified in osteoclast-rich osteopetrosis, all of which impair the ability of osteoclasts to resorb bone. ${ }^{33}$

\section{SOST}

The SOST gene on chromosome 17q21 encodes sclerostin, a protein that is produced almost exclusively by osteocytes and which inhibits bone formation, probably by preventing members of the Wnt family binding to the LRP5 receptor. ${ }^{34}$

\section{TNFRSF11B}

The TNFRSF11B gene on chromosome 8 encodes osteoprotegerin (OPG), which is an endogenously produced inhibitor of bone resorption. ${ }^{35}$ OPG plays a critical role in bone metabolism and has been the subject of several candidate gene association studies. ${ }^{36}$

\section{Other Candidate Genes for Susceptibility to Osteoporosis}

\section{COL1A1}

Type I collagen is the major protein of bone and is also a heterotrimer consisting of $\alpha 1$ and $\alpha 2$ protein chains that are encoded by the COL1A1 and COL1A2 genes, respectively.

Polymorphisms of the COL1A1 gene have been studied extensively in relation to BMD and osteoporotic fracture.

The "T" allele of this polymorphism has been associated with BMD and/or osteoporotic fractures in several studies, ${ }^{37,38}$ but negative results have also been reported. ${ }^{39,40}$

Nonetheless, a retrospective meta-analysis of published studies showed that the COL1A1 Sp1 polymorphism was significantly associated with osteoporotic fractures ${ }^{41}$ and bone density, ${ }^{42,43}$ with evidence of an allele dose effect.

\section{TGFB1}

TGF1 encoded by the TGFB1 gene is thought to act as F, a coupling factor between bone resorption and bone formation. This gene is been associated with low BMD, increased bone turnover, and osteoporotic fracture in one study from Denmark. $^{44}$

\section{VDR}

The active metabolites of vitamin D play an important role in regulating bone cell function and maintaining serum calcium homeostasis by binding to the vitamin D receptor(VDR), which regulates expression of various response genes. The VDR gene has been extensively studied as a potential candidate for regulating genetic susceptibility to osteoporosis. Large number of association studies between VDR alleles and BMD 
and/or fracture were subsequently performed, but the results were conflicting, probably because none of the studies was adequately powered. ${ }^{45}$

\section{Syndromes Associated Due to Genetic Impairment}

The genetic impact on syndromes is tremendous, and unfortunately it leads to not only suffering lasting for a lifetime but also continues for many generations. Genes not only mediates inflammatory reactions but they are also responsible for various syndromes.

\section{Papillon-Lefevre Syndrome}

Papillon-Lefevre syndrome is one such syndrome, characterized by different dermatological manifestations, with periodontitis being presented as systemic manifestation. It is an autosomal recessive condition that impairs the patient socially and psychologically and also his/her aesthetic wellbeing at a very young age, due to partial or complete edentulism. It is thought to be as a secondary result to the mutation of the cathepsin $\mathrm{C}$ gene.

Various studies have shown that the immune-related cells like the polymorphonuclear leucocytes and the macrophages and their precursors were affected. This syndrome has shown a genetic predisposition, with a greater frequency of occurrence in consanguineous offspring being noted in approximately one-third of the cases. It usually occurs during the first 4 to 5 years of age, and affects the primary dentition with a periodontal involvement, leading to an early exfoliation of the primary dentition. And as the permanent teeth erupt, the same sequence of events recurs, leading to the exfoliation of the permanent dentition. ${ }^{46,47}$ This extreme condition is a huge challenge in total rehabilitation of the existing denture.

\section{Osteogenesis Imperfecta}

Osteogenesis imperfecta is a syndrome characterized by lowbone mass and a marked increase in bone fragility. The disease is most often caused by mutations in the COL1A1 and COL1A2 genes, but recent work has shown that mutations in the CRTAP, LEPRE, and PPIB genes, which form a protein complex necessary for prolyl-3-hydroxylation of collagen, can cause recessive forms of osteogenesis imperfecta. ${ }^{48,49}$

\section{Ectodermal Dysplasia}

The term ectodermal dysplasia is used to designate a heterogenous group of disorders characterized by a constellation of findings involving a primary defect of the skin, teeth, and appendageal structures including hair, nail, exocrine and sebaceous glands. Dental manifestations include conical or pegged teeth, hypodontia or complete anodontia, and delayed eruption of permanent teeth. ${ }^{50}$ The different types of ectodermal dysplasia are caused by the mutation or deletion of certain genes like EDA, EDAR, and EDARADD located on different chromosomes. ${ }^{51}$

Hypohidrotic ectodermal dysplasia (HED) is usually transmitted as an X-linked recessive trait in which the gene is carried by the female and manifested in male. In X-linked form carrier mothers exhibit minimal expression in the form of hypodontia and/or conical teeth and spottily reduced sweating. ${ }^{50,51}$

\section{Ehlers-Danlos Syndrome (EDS)}

EDS is a genetic disorder that can be caused by mutations in several different genes, including COL5A1, COL5A2, COL1A1, COL3A1, TNXB, PLOD1, COL1A2, FKBP14, and ADAMTS2. Mutations in these genes usually change the structure, production, and/or processing of collagen or proteins that interact with collagen. Collagen provides structure and strength to connective tissues throughout the body. A defect in collagen can weaken connective tissues in the skin, bones, blood vessels, and organs, resulting in the signs and symptoms of EDS. ${ }^{52}$ Early-onset generalized periodontitis is one of the most significant oral manifestations of the syndrome. This can lead to the premature loss of deciduous and permanent teeth.

\section{Chediak-Higashi Syndrome (CHS)}

It is a disease of intracellular vacuolar and granule fusion caused by autosomal recessive mutations to the CHS1 gene (the human equivalent of the mouse LYST gene). CHS has both hematopoietic and neurological manifestations. Clinical symptoms include recurrent infections, with organisms normally eliminated by phagocytosis, peripheral neuropathy, partial oculocutaneous albinism, slight mental retardation, platelet dysfunction, severe periodontitis, and a sometimes fatal infiltration of lymphocytes and macrophages into various organs.

Periodontal disease and bone loss of dental alveoli associated with various microorganisms are common. The homeostasis of neutrophils is tightly regulated through coordinated bone marrow production, release into the circulation, transmigration to and activation in peripheral tissues, and clearance of senescent neutrophils. Dysregulation of any of these homeostatic mechanisms at any age can cause severe periodontitis. Accordingly, both impaired and excessive neutrophil activity (in terms of numbers or immune function) can precipitate periodontitis. Neutrophil defects of congenital origin (e.g., congenital neutropenia, leukocyte adhesion deficiency, and CHS) are associated with cutaneous and systemic infections and early-onset forms of periodontitis, affecting both the primary and permanent dentitions of children. ${ }^{53,54}$

\section{Conclusion}

Bone, dental loss, and defects caused by diseases have become a global concern, with high incidence, which seriously affects the health and life quality of the whole population. At many times, it is best to attempt to intervene in the disease, as it is challenging to remove the cause at the genetic level. Dentists could be the first persons to identify these rare conditions at an early stage, making it particularly necessary for them to adequately grasp the related clinical features. Understanding the effects of genes on bone modulation will shed more light on the pathogenesis and therapeutics of bone and teeth.

\section{Conflict of Interest}

None declared. 


\section{References}

1 Wellik DM, Capecchi MR. Hox10 and Hox11 genes are required to globally pattern the mammalian skeleton. Science 2003;301 (5631):363-367

2 Adler CP. Bones and bone tissue; normal anatomy and histology. In Bone Diseases New York: Springer-Verlag; 2000:1-30

3 Zaidi M. Skeletal remodeling in health and disease. Nat Med 2007; 13(07):791-801

4 Claflin RS. Healing of disturbed and undisturbed extraction wounds. J Am Dent Assoc 1936;23:945-959

5 Atwood DA. Reduction of residual ridges: a major oral disease entity. J Prosthet Dent 1971;26(03):266-279

6 Resorption level of edentulous alveolar bone in normal, osteopenia and osteoporosis postmenopausal women. J Prosthet Dent 2012;8(03):141-146

7 Frutos R, Rodríguez S, Miralles-Jorda L, Machuca G. Oral manifestations and dental treatment in menopause. Med Oral 2002;7 (01):26-30, 31-35

8 Lerner UH. Inflammation-induced bone remodeling in periodontal disease and the influence of post-menopausal osteoporosis. J Dent Res 2006;85(07):596-607

9 Cecconi BT, Asgar K, Dootz E. Clasp assembly modifications and their effect on abutment tooth movement. J Prosthet Dent 1972; 27(02):160-167

10 Wactawski-Wende J. Periodontal diseases and osteoporosis: association and mechanisms. Ann Periodontol 2001;6(01):197-208

11 Martínez-Maestre MA, González-Cejudo C, Machuca G, Torrejón R, Castelo-Branco C. Periodontitis and osteoporosis: a systematic review. Climacteric 2010;13(06):523-529

12 Kornman KS, di Giovine FS. Genetic variations in cytokine expression: a risk factor for severity of adult periodontitis. Ann Periodontol 1998;3(01):327-338

13 Nishimura I, Garrett N. Impact of Human Genome Project on treatment of frail and edentulous patients. Gerodontology 2004; 21(01):3-9

14 Song J-H, Lee J-H. Single nucleotide polymorphisms and haplotypes in vascular endothelial growth factor gene and residual ridge resorption of mandible in Korean population. J Biomaterials Nanobiotechnology 2014;5:39-43

15 AlSheikh HA, AlZain S, Shaik JP, Bhogoju S, Warsy A, Reddy Parine $\mathrm{N}$. Two novel SNPs in genes involved in immune response and their association with mandibular residual ridge resorption. Saudi J Biol Sci 2020;27(03):846-852

16 Jahangiri L, Devlin H, Ting K, Nishimura I. Current perspectives in residual ridge remodeling and its clinical implications: a review. J Prosthet Dent 1998;80(02):224-237

17 Paek J, Oh Y, Kim J, Lee JH. Single nucleotide polymorphisms in HIF- $1 \alpha$ gene and residual ridge resorption (RRR) of mandible in Korean population. Gene Expr 2015;16(03):137-144

$18 \mathrm{Kim} \mathrm{JH}$, Oh MY, Paek J, Lee J. Association between FGFR1OP2/ wit3.0 polymorphisms and residual ridge resorption of mandible in Korean population. PLoS One 2012;7(08):e42734

19 Kim JJ, Shon HC, Chang JH, et al. HIF-1 Alpha and VEGF expression in fracture healing. J Korean Orthop Assoc 2008;43:479487

20 Zhao T, Lv J, Zhao J, Nzekebaloudou M. Hypoxia-inducible factor1alpha gene polymorphisms and cancer risk: a meta-analysis. J Exp Clin Cancer Res 2009;28:159-169

21 Atwood DA. Postextraction changes in the adult mandible as illustrated by microradiographs of midsagittal sections and serial cephalometric roentgenograms. J Prosthet Dent 1963;13: 810-824

22 Nedelman C, Gamer S, Bernick S. The alveolar ridge mucosa in denture and non-denture wearers. J Prosthet Dent 1970;23(03): 265-273

23 Suwanwela J, Lee J, Lin A, et al. A genetic association study of single nucleotide polymorphisms in FGFR1OP2/wit3.0 and long-term atrophy of edentulous mandible. PLoS One 2011;6(01):e16204
24 Gunsolley JC, Califano JV, Koertge TE, Burmeister JA, Cooper LC, Schenkein HA. Longitudinal assessment of early onset periodontitis. J Periodontol 1995;66(05):321-328

25 Baer PN. The case for periodontosis as a clinical entity. J Periodontol 1971;42(08):516-520

26 Boughman JA, Halloran SL, Roulston D, et al. An autosomaldominant form of juvenile periodontitis: its localization to chromosome 4 and linkage to dentinogenesis imperfecta and Gc. J Craniofac Genet Dev Biol 1986;6(04):341-350

27 Yucel-Lindberg T, Båge T. Inflammatory mediators in the pathogenesis of periodontitis. Expert Rev Mol Med 2013;15:e7

28 Stefan A. Hienz, Sweta Paliwal, Saso Ivanovski. Mechanisms of Bone Resorption in Periodontitis. Hindawi Publ Cor J Immunol Research 2015;10;. Doi: 10.1155/2015/615486

29 Liu D, Xu JK, Figliomeni L, et al. Expression of RANKL and OPG mRNA in periodontal disease: possible involvement in bone destruction. Int J Mol Med 2003;11(01):17-21

30 Udagawa N, Takahashi N, Jimi E, et al. Osteoblasts/stromal cells stimulate osteoclast activation through expression of osteoclast differentiation factor/RANKL but not macrophage colony-stimulating factor: receptor activator of NF-kappa B ligand. Bone 1999; 25(05):517-523

31 Styrkarsdottir U, Halldorsson BV, Gretarsdottir S, et al. Multiple genetic loci for bone mineral density and fractures. N Engl J Med 2008;358(22):2355-2365

32 Styrkarsdottir U, Halldorsson BV, Gretarsdottir S, et al. New sequence variants associated with bone mineral density. Nat Genet 2009;41(01):15-17

33 Gong Y, Vikkula M, Boon L, et al. Osteoporosis-pseudoglioma syndrome, a disorder affecting skeletal strength and vision, is assigned to chromosome region 11q12-13. Am J Hum Genet 1996; 59(01):146-151

34 Balemans W, Van Wesenbeeck L, Van Hul W. A clinical and molecular overview of the human osteopetroses. Calcif Tissue Int 2005;77(05):263-274

35 Riches PL, McRorie E, Fraser WD, Determann C, van't Hof R, Ralston $\mathrm{SH}$. Osteoporosis associated with neutralizing autoantibodies against osteoprotegerin. N Engl J Med 2009;361(15):1459-1465

36 Choi JY, Shin A, Park SK, et al. Genetic polymorphisms of OPG, RANK, and ESR1 and bone mineral density in Korean postmenopausal women. Calcif Tissue Int 2005;77(03):152-159

37 Garnero P, Borel O, Grant SF, Ralston SH, Delmas PD. Collagen Ialpha1 Sp1 polymorphism, bone mass, and bone turnover in healthy French premenopausal women: the OFELY study. J Bone Miner Res 1998;13(05):813-817

38 Langdahl BL, Ralston SH, Grant SF, Eriksen EF. An Sp1 binding site polymorphism in the COLIA1 gene predicts osteoporotic fractures in both men and women.J Bone Miner Res 1998;13(09):1384-1389

39 Berg JP, Lehmann EH, Stakkestad JA, Haug E, Halse J. The Sp1 binding site polymorphism in the collagen type I alpha 1 (COLIA1) gene is not associated with bone mineral density in healthy children, adolescents, and young adults. Eur J Endocrinol 2000; 143(02):261-265

40 Heegaard A, Jorgensen HL, Vestergaard AW, Hassager C, Ralston $\mathrm{SH}$. Lack of influence of collagen type Ialpha1 Sp1 binding site polymorphism on the rate of bone loss in a cohort of postmenopausal danish women followed for 18 years. Calcif Tissue Int 2000;66(06):409-413

41 Efstathiadou Z, Tsatsoulis A, Ioannidis JP. Association of collagen Ialpha $1 \mathrm{Sp} 1$ polymorphism with the risk of prevalent fractures: a meta-analysis. J Bone Miner Res 2001;16(09):1586-1592

42 Mann V, Ralston SH. Meta-analysis of COL1A1 Sp1 polymorphism in relation to bone mineral density and osteoporotic fracture. Bone 2003;32(06):711-717

43 Lohmueller KE, Pearce CL, Pike M, Lander ES, Hirschhorn JN. Metaanalysis of genetic association studies supports a contribution of common variants to susceptibility to common disease. Nat Genet 2003;33(02):177-182 
44 Langdahl BL, Knudsen JY, Jensen HK, Gregersen N, Eriksen EF. A sequence variation: 713-8delC in the transforming growth factorbeta 1 gene has higher prevalence in osteoporotic women than in normal women and is associated with very low bone mass in osteoporotic women and increased bone turnover in both osteoporotic and normal women. Bone 1997;20(03):289-294

45 Singla A, Sheikh S, Jindal SK, Brar R. The Papillon Lefevre syndrome: a bridge between a dermatologist and a dentist. J Clin Exp Dent 2010;2(01):e43-e46

46 Sreeramulu B, Haragopal S, Shalini K, Sudha MD, Kiran G. The prosthodontic management of a young edentulous patient with the papillon lefevre syndrome-a rare case report. J Clin Diagn Res 2012;6(10):1808-1811

47 Barnes AM, Chang W, Morello R, et al. Deficiency of cartilageassociated protein in recessive lethal osteogenesis imperfecta. $\mathrm{N}$ Engl J Med 2006;355(26):2757-2764

48 Cabral WA, Chang W, Barnes AM, et al. Prolyl 3-hydroxylase 1 deficiency causes a recessive metabolic bone disorder resembling lethal/severe osteogenesis imperfecta. Nat Genet 2007;39(03): 359-365
49 Gopinath VK, Manoj KM, Mahesh K. Hypohidrotic ectodermal dysplasia-a case report. J Indian Soc Pedod Prev Dent 1999;17 (03):90-92

50 Wright JT, Grange DK, Fete M. Hypohidrotic ectodermal dysplasia. In: Adam MP, Ardinger HH, Pagon RA, et al., eds. GeneReviews ${ }^{\circledR}$ [Internet]. Seattle (WA): University of Washington, Seattle; 2017 : 1993-2021. Available at: https://www.ncbi.nlm.nih.gov/books/ NBK1112/

51 Gorlin RJ, Pindborg JJ, Cohen MM. Syndromes of Head and Neck. 20th ed. New York: Mc Graw Hill; 1976:379-385

52 Açil Y, Mobasseri AE, Warnke PH, Terheyden H, Wiltfang J, Springer I. Detection of mature collagen in human dental enamel. Calcif Tissue Int 2005;76(02):121-126

53 Barbosa MDFS, Nguyen QA, Tchernev VT, et al. Identification of the homologous beige and Chediak-Higashi syndrome genes. Nature 1996;382(6588):262-265

54 Hajishengallis E, Hajishengallis G. Neutrophil homeostasis and periodontal health in children and adults. J Dent Res 2014;93(03): 231-237 